fact that the turnover of nurses in the rehabilitation unit at the end of the period under review was less than in any other medical ward of the hospital.

\section{Conclusions}

A ward that caters for patients with a variety of disabilities has now been operating in a large district general hospital for over three years. The patients referred to this service have almost exclusively had severe or complex neurological disability, or both. The policy of accepting patients with unstable or deteriorating conditions requires clear understanding and agreement about ward policy and the objectives of the admission, but the reports later received from the patients themselves lead us to believe that this policy is worth while.

Accurate initial diagnostic and functional assessment, regular review, and setting realistic, agreed goals for treatment during both the inpatient phase and prolonged follow up are increasingly seen to be of paramount importance. The processes by which these are achieved have evolved considerably and will undoubtedly continue to do so.

As the information presented in this paper is uncontrolled it does not establish that the therapy and training undertaken by the patients altered the natural course of their conditions. It is difficult to evaluate the effectiveness of measures intended to accelerate or extend the process of rehabilitation because the patients are difficult to match, therapy cannot be administered in a blinded fashion, and objective evaluation of results is imperfect. Nevertheless, some progress has been made in the assessment of stroke units, ${ }^{4-6}$ and an important future aim of the ward will be to assess objectively the treatment of disabling conditions.

We thank Ted Cantrell, Cyrus Cooper, Sally Gore, Nina Melville, Tony Thompson, Steve Wilkinson, and Martine Wright for helpful comments on the paper and Belinda Hatch for word processing.

1 Royal College of Physicians. Physical disability in 1986 and beyond. $f R$ Coll Physicians Lond 1986;20:161-94.

Mahoney FI, Barthel DW. Functional evaluation: the Barthel index. Md State Med F 1965;14:61-5.

3 Donaldson SW, Wagner CC, Gresham GE. A unified ADL evaluation form. Arch Phys Med Rehabil 1973;54:175-9.

4 Stevens RS, Ambler NR, Warren MD. A randomised controlled trial of a stroke rehabilitation ward. Age Ageing 1984;13:65-75.

5 Garraway WM, Akhtar AJ, Prescott RJ, Hockey L. Management of acute stroke in the elderly: preliminary results of a controlled trial. $\mathrm{Br} \mathrm{Med}$ 1980;280:1040-3

6 Garraway WM, Akhtar AJ, Hockey L, Prescott RJ. Management of acute stroke in the elderly: follow up of a controlled trial. $\mathrm{Br}$ Med $\mathcal{F} 1980 ; 281$ : $827-9$

(Accepted 26 August 1988)

\title{
Use and abuse of performance indicators
}

\author{
Paul W Skinner, David Riley, E Maelor Thomas
}

\begin{abstract}
An audit was performed by this department after allegations by the regional health authority of low productivity. It was found that the health authority had underestimated the number of operations performed in 1983 by only $5 \%$, but an inexact classification and grading of operations had led to errors in the performance indicators of $19.8 \%$ for the "weighted number of operations" and $34.5 \%$ for the "number of major operations per consultant." When the throughput of orthopaedic departments in districts was compared by the regional health authority it was found that such errors in performance indicators had been further compounded by the inconsistent use of population data and incorrect data on medical staffing.

Medical practitioners and the health authorities are alerted to this amplification of inaccurate data. Other methods for assessing trauma and orthopaedic surgery are proposed, such as a simplification of the Office of Population Censuses and Surveys classification of surgical operations, grading operations based on time spent in the operating theatre, and provision of computer programs to code for diagnosis and operation when writing discharge summaries.
\end{abstract}

Department of Trauma and Orthopaedics, King's College Hospital, Denmark Hill, London SE5 9RS Paul W Skinner, FRCS, senior registrar

David Riley, FRCS, registrar

E Maelor Thomas, FRCS,

consultant

Correspondence to: $\mathrm{Mr} \mathrm{P}$ W Skinner, 17 Kingston Street, Nedlands, Perth, Western Australia 6009.

\section{Introduction}

Surgical audit is not new. Previous studies have usually been conducted internally for clinical research and as such were concerned with diagnosis, treatment, and complications. ${ }^{1-3}$ By contrast, after the National Health Service Management Enquiry ${ }^{4}$ external audit by health authorities has become more frequent but with the different purpose of assessing performance in terms of workload and use of resources.

When data for the number of patients treated surgically are ranked into major, intermediate, or minor categories of operation, weighted, and then related to population, hospital beds, or manpower the data become a "performance indicator." The first set of performance indicators was introduced in $1983,{ }^{5}$ and faced with limited resources managers are making increasing use of such indicators to compare output and to set future targets.

Under the NHS planning system each health authority is required every five years to produce a 10 year strategic plan. The plan produced by the South East Thames Regional Health Authority for 1985-94 contained statements alleging low performance in replacing hips in this and other health districts in the region, based on figures for 1983 .

The trauma and orthopaedic department of this district was so surprised by these unqualified allegations that it was prompted to perform its own audit and examine the existing methods of assessing performance. The trauma and orthopaedic department of Camberwell Health District serves a catchment population of 230100 for acute admissions. There are four consultants, two senior registrars, two registrars, and four house officers. Trauma, which accounts for half the total number of admissions, is managed at King's College Hospital (50 beds), while elective orthopaedic admissions are managed at Dulwich Hospital (40 beds).

\section{Methods}

TRAUMA AND ORTHOPAEDIC OPERATIONS

The operation registers for 1983 were examined and the number, type, and duration of operations noted.

\section{Existing classification and grading of operations}

Operations were initially classified and graded according to the current practice of the regional 
health authority, but these methods proved to be unsatisfactory. The third (1975) revision of the Office of Population Censuses and Surveys Classification of Operations, ${ }^{?}$ on which current performance indicators are based, was outdated; advances in surgery over the past 20 years such as arthroscopic or microscopic

TABLE I-Proposed grading of trauma and orthopaedic operations, with four of the commonest examples in each category. Duration of operation includes time taken for anaesthesia, positioning, operating, waking the patient, and time between patients

\begin{tabular}{lc}
\hline \multicolumn{1}{c}{ Grade of operation } & $\begin{array}{c}\text { Mean duration } \\
\text { in minutes } \\
\text { (range) }\end{array}$ \\
\hline Minor: & $27(20-39)$ \\
Epidural & \\
Aspiration of joint & \\
Examination under anaesthesia & \\
Change of plaster of Paris/dressings & \\
Intermediate: & \\
Closed reduction of fracture and plaster of Paris & \\
Removal of implant & \\
Release of carpal tunnel & \\
Diagnostic arthroscopy & 96 (80-119) \\
Major: & \\
Open reduction/fixation of fracture \\
Hemiarthroplasty \\
Meniscectomy (open/arthroscopy) \\
Complicated hand injury \\
Major plus: \\
Knee ligament reconstruction \\
Discectomy and laminectomy \\
Total hip replacement \\
Total knee replacement \\
Complex major: \\
Scoliosis (anterior/posterior fusion) \\
Revision hip replacement \\
Revision knee replacement \\
Nerve graft
\end{tabular}

TABLE II-Comparison of external and internal audit for trauma and orthopaedic data and performance indicators for 1983

\begin{tabular}{|c|c|c|c|}
\hline & $\begin{array}{l}\text { Regional health } \\
\text { authority audit }\end{array}$ & $\begin{array}{c}\text { Internal } \\
\text { audit }\end{array}$ & $\begin{array}{c}\text { Error } \\
(\%)\end{array}$ \\
\hline $\begin{array}{l}\text { Number of operations: } \\
\text { Major } \\
\text { Intermediate } \\
\text { Minor } \\
\text { Not graded }\end{array}$ & $\begin{array}{r}622 \\
1093 \\
493 \\
23\end{array}$ & $\begin{array}{r}811 \\
1118 \\
419\end{array}$ & \\
\hline Total & 2231 & 2348 & $5 \cdot 1$ \\
\hline $\begin{array}{l}\text { Performance indicators: } \\
\text { Major operations }(\% \text { of total) } \\
\text { Major operations per consultant } \\
\text { Weighted number of operations } \\
\text { Weighted operations per } \\
\text { consultant }{ }^{\star}\end{array}$ & $\begin{array}{r}29 \\
158 \\
24 \quad 263\end{array}$ & $\begin{array}{r}35 \\
213 \\
29076\end{array}$ & $\begin{array}{c}6 \\
34 \cdot 5 \\
19 \cdot 8\end{array}$ \\
\hline
\end{tabular}

*Weighting of 20,10, and 4 units applied to number of major, intermediate, and minor operations respectively, according to current practice of South East Thames Regional Health Authority.

TABLE III - Number of “hip replacements" performed in 1983 according to regional health authority and internal audits

\begin{tabular}{|c|c|c|c|c|}
\hline $\begin{array}{l}\text { Office of Population Censuses } \\
\text { and Surveys code }\end{array}$ & Operation & Regional health authority audit & Internal audit & $\begin{array}{c}\text { Error } \\
(\%)\end{array}$ \\
\hline 810 & Total hip replacement & & & \\
\hline 810.1 & Muller & & & \\
\hline 810.2 & McKee (Stanmore) & 79 & 92 & \\
\hline 810.3 & Cup & 1 & & \\
\hline 810.4 & Freemans & 23 & & \\
\hline 810.5 & Revision & 2 & 17 & \\
\hline 810.6 & Wagner & 3 & & \\
\hline 810.8 & & 24 & & \\
\hline 810.9 & Charnley & 8 & 31 & \\
\hline 811 & Other hip arthroplasty & & & \\
\hline 811.1 & Acetabuloplasty & & 1 & \\
\hline 811.2 & Thompsons & 4 & 42 & \\
\hline 811.3 & Charles & & & \\
\hline 811.4 & Salters & 1 & & \\
\hline 811.5 & Revision & $i$ & & \\
\hline 811.6 & Girdlestone & & 3 & \\
\hline 811.8 & & 13 & & \\
\hline 811.9 & Moor (austin) ${ }^{\star}$ & 3 & 2 & \\
\hline Total & & 162 & 188 & 16 \\
\hline
\end{tabular}

$\star$ As written. surgery were almost impossible to classify, while even well established procedures could be classified in several different ways.

The present method used by the region for ranking procedures as major, intermediate, or minor also proved to be inappropriate, bearing no relation to either the length or the complexity of the procedure. Reducing and plating a fracture is graded an intermediate operation and weighted 10 points, while removing the metalwork is graded a major operation and weighted 20 points. A three hour operation such as a nerve graft is graded intermediate, whereas a half hour Keller operation for bunions is graded major.

\section{Adopted classification and grading of operations}

Alternative methods of classifying operations were examined. Methods that combined diagnosis and procedure into one code ${ }^{38}$ were more simple, with less than 100 codes, and yet were more descriptive for clinical research than the classification of the Office of Population Censuses and Surveys.

In order to grade operations the mean of 20 recorded times for any particular procedure was calculated (table I). The duration of an operation included the time taken to anaesthetise, position, and operate on the patient, and the interval between patients, and therefore represents theatre use and not just operating time. Procedures were then graded as minor (duration under 40 minutes), intermediate (40-80 minutes), or major (over 80 minutes) to compare the results with Hospital Activity Analysis. A more accurate representation of theatre use, however, would be given by the additional categories "major plus" and "complex major operation" for the growing number of time consuming operations taking 120-180 minutes and 180-240 minutes respectively.

The results of this grading gave resuits so similar to the BUPA grading of operations ${ }^{8}$ that a modified version of the BUPA grading was used both for classifying and then for grading procedures.

\section{STAFFING AND POPULATION}

Figures for the orthopaedic medical staffing of the region in 1983 were collected from colleagues in other health districts and then compared with data published by the region for 1983.6 Population statistics were obtained from the regional strategic plan. ${ }^{6}$

\section{Results}

A comparison of the internal audit with Hospital Activity Analysis data and regional health authority performance indicators for 1983 showed the following inaccuracies:

\section{TRAUMA AND ORTHOPAEDIC OPERATIONS (table II)}

The health authority had underestimated the total number of operations performed by $5 \%$, but the use of an inappropriate grading of operations had led to an underestimate of the number of major operations by $30 \%$. Performance indicators were correspondingly affected, with an error of nearly $20 \%$ for the "weighted number of operations" and, despite accurate figures on medical staffing, an error of $34 \cdot 5 \%$ for the "number of major operations per consultant."

Of the total number of operations attributed to the trauma and orthopaedic department on the computer printout of Hospital Activity Analysis data, 2\% would normally be regarded as well outside our capabilities. These operations ranged from "tonsillectomy" and "corneal replacement" to "repair or replacement of the bladder" (sic). None of us admits to such versatility, and we wonder what the initial orthopaedic treatment was. 
TABLE IV-Comparison of methods of rating trauma and orthopaedic operations, with the mean duration of each grade of operation where known

\begin{tabular}{|c|c|c|c|c|c|}
\hline \multirow[b]{2}{*}{ Grade of operation } & \multirow{2}{*}{$\begin{array}{l}\text { South East Thames } \\
\text { Regional Health Authority } \\
\text { rating } \\
\text { (units) }\end{array}$} & \multicolumn{2}{|c|}{ Southampton, 1974} & \multicolumn{2}{|c|}{ King's, 1987} \\
\hline & & $\underset{(\min )}{\text { Duration }}$ & $\begin{array}{l}\text { Rating } \\
\text { (units) }\end{array}$ & $\underset{(\mathrm{min})}{\text { Duration }}$ & $\begin{array}{l}\text { Rating } \\
\text { (units) }\end{array}$ \\
\hline Minor & 4 & 27 & 3 & 27 & 1 \\
\hline Intermediate & 10 & 40 & 4 & 53 & 2 \\
\hline Major (total) & 20 & 93 & 9 & 115 & 4 \\
\hline Major ${ }^{\star}$ & & & & 96 & 3 \\
\hline Major plus ${ }^{\star}$ & & & & 152 & 5 \\
\hline Complex major ${ }^{\star}$ & & & & 218 & 7 \\
\hline
\end{tabular}

^BUPA subcategories for major operations.

\section{HIP REPLACEMENTS (table III)}

The number of operations recorded by Hospital Activity Analysis under the existing Office of Population Censuses and Surveys classification for hip replacement and arthroplasty had been underestimated by $16 \%$. The gross number of total hip replacements had been correctly recorded by Hospital Activity Analysis, but this was purely fortuitous: operations not performed had been recorded, and the regional and district health authorities were each interpreting the same classification differently, after modification some years previously.

Under the 1975 classification by the Office of Population Censuses and Surveys operations for three very different clinical problems - congenital disorders of the hip, arthritis of the hip, and fracture of the neck of the femur - were difficult to distinguish.

\section{MEDICAL STAFFING}

Although correct for this health district, the regional figures on medical staffing for 1983 in each of the other five districts studied were often inaccurate and in one district (West Lambeth) underestimated by threefold. These errors became pertinent when the productivity of districts was compared by the regional health authority. ${ }^{6}$

Moreover, it was found that when assessing surgical staffing for performance indicators a consultant is counted as one unit and senior registrars as half a unit. No other medical staff who may regularly operate, such as registrars, senior house officers, or clinical assistants, are counted.

\section{Population}

Various population statistics quoted in the regional strategic plan $^{6}$ were inconsistently used when comparing the manpower of various districts. For the Camberwell Health District a "resident population" of 213200 or 215000 , an "acute catchment population" of 238900 , and an "age adjusted catchment population" of 230100 were each used indiscriminately when presumably the last is the more reliable population figure for comparison of the potential workload of districts.

\section{Discussion}

If performance indicators are to be of use in planning then accurate figures are essential. In this study inaccuracies were found at all levels and were principally errors in the collection, classification, grading, and interpretation of data. Although the study was confined to one surgical specialty in one health region, we would be surprised if similar potential errors do not exist for other specialties and for other regions.

\section{COLLECTION}

Previous authors ${ }^{9}$ reported Hospital Activity Analysis information to be inaccurate when investi- gating a particular diagnosis or operation and to underestimate the number of patients treated by as much as $22 \%$ despite diligent completion of HMRI (a summary of diagnostic and operation details for each admission). Perhaps the Hospital Activity Analysis department of this district should be congratulated for having a shortfall in the number of patients treated by only $5 \%$.

This discrepancy between medical and Hospital Activity Analysis audit should improve with the implementation of the findings of the Korner report, ${ }^{9}$ whereby several "consultant episodes" may be recorded for each admission and thus more accurately represent the resources used. No longer would a patient with multiple injuries be coded arbitrarily under one consultant, and one operation, without regard to other "consultant episodes" required for the other injuries and specialist operations.

\section{CLASSIFICATION}

Before carrying out this study we were ignorant of the difficulties in classifying information on inpatients. The third (1975) revision of the Office of Population Censuses and Surveys classification of surgical operations, on which current performance indicators are based, was recognised as being out of date, and the fourth revision, introduced on 1 April 1988, is an improvement in terms of diversity. But with nearly 2000 codes possible for trauma and orthopaedic operations alone, the latest classification is too complex for the occasional user and the risk of misclassifying information high

By contrast we found that the systems that combined diagnosis with procedure in under 100 codes, although not capable of distinguishing the minutiae of diagnostic, anatomical, and surgical detail, were much easier to use and therefore more accurate. And a simpler system allows medical staff to code when writing a discharge summary and help to improve the accuracy.

Faced with the additional problem of insufficient secretarial support we are following the lead of others and hope to obtain a microcomputer that will simplify the writing of discharge summaries, a copy of which would be sent to Hospital Activity Analysis.

\section{GRADING}

Whatever classification is used a ranking of operations is needed that represents the resources used (table IV). We have been unable to trace the origin of the inappropriate grading currently in use in South East Thames Regional Health Authority, and, as far as we can ascertain, throughout the NHS; South East Thames region, the Royal Colleges of Surgeons, and the Office of Population Censuses and Surveys all deny responsibility.

The Duthie report described in detail the difficulties of collecting and interpreting data for trauma and orthopaedics ${ }^{11}$ and in the absence of a nationally agreed method of rating operations recommended the Southampton system ${ }^{12}$ (table IV). The times recorded in our study for major operations were considerably longer than those obtained in Southampton, reflecting the increasing complexity of surgery since 1974. If major operations are further subdivided into major, major plus, and complex major operations (as in the BUPA grading) for those procedures taking more than two hours, then we believe a more accurate representation of theatre use would be shown - the internal audit for 1986 showed a $10 \%$ increase on 1983 for the number of major plus and complex major operations.

We recommend that a limited listing of perhaps the 100 most common or important diagnosis/procedures 
for each surgical specialty could be agreed on by the various specialist associations and the colleges of surgeons. Such a system could be allocated an agreed coding within the new Office of Population Censuses and Surveys classification and a ranking from the BUPA grading of surgical procedures. The more important medical-and therefore economicconditions could then be readily and reliably identified.

\section{INTERPRETATION}

Having achieved an accurate base to inpatient data, the many other factors that influence surgical throughput must be correctly recorded and taken into account when comparing performance indicators. Essential among the variables that need to be considered when comparing performance is (as recommended by the Duthie report ${ }^{10}$ ) a distinction between trauma and orthopaedic admissions. An elective orthopaedic patient cannot be admitted if a trauma patient is lying in that bed, and this competition between emergency and waiting list admissions is true for all specialties. Accordingly, if an elective operation such as a hip replacement is selected for comparing performance we advocate that the competing trauma load be taken into account.

Thus there are many problems in accurately representing workload in one hospital. Much effort has been expended in the past ${ }^{71} 11$ in an attempt to improve the accuracy of information on inpatients, and the difficulties of devising suitable methods should not be underestimated. Our results, however, lead us to conclude that existing methods are ton flawed to allow an accurate or meaningful assessment of performance.

\section{Recommendations}

(1) Simplify and clarify the 1988 Office of Population Censuses and Surveys classification of surgical operations.

(2) Use the BUPA grading of surgical operations, based on time spent in the operating theatre.

(3) Provide adequate computer support to enable medical staff to code for diagnosis and operation at the time of writing discharge summaries.

1 Gough MH, Kettlewell MGW, Marks CG, Holmes SJK, Holderness J. Audit: an annual assessment of the work and performance of a surgical firm in a regional teaching hospital. Br Med f 1980;281:913-8.

2 Bunker TD, Ackroyd CE, Griffiths HED. Orthopaedic audit: one year's experience in a district general hospital. Ann R Coll Surg Engl 1984;66: 428-31.

3 Broughton NS, Bunker TD, Ackroyd CE. The use of a microcomputer for inpatient audit in an orthopaedic department. Ann R Coll Surg Engl 1985;67:259-62.

4 Department of Health and Social Services. National Health Service management enquiry. London: DHSS, 1983. (Griffiths report.)

5 Department of Health and Social Security. Performance indicators. National summary for 1981 . London: HMSO, 1983.

6 South East Thames Regional Health Authority. Strategic plan 1985-1994. Bexhill-on-Sea, East Sussex: Information Service, SETRHA, July 1985.

7 Office of Population Censuses and Surveys. Classification of operations. Third revision. London: HMSO, 1975.

8 British United Provident Association. BUPA grading of surgical procedures. Provident House, Essex St, London: British United Provident Association Ltd, 1985.

9 Whates PD, Birzgalis AR, Irving M. Accuracy of hospital activity analysis codes. Br Med J 1982;284:1857-8.

10 Health Services Information Steering Group. A report on the collection and use of information about clinical activity in the NHS. London: HMSO, 1980. (Korner report.)

11 Working Party to the Secretary of State for Social Services. Orthopaedic services: waiting time for out-patient appointments and in-patient treatment. London: HMSO, 1981. (Duthie report.)

12 Wood SK, Sutton A, Allen E. An admission policy for a 120 bed ward unit. Information for action. London: DHSS, 1974. (Proceedings of a symposium held at Northwick Park Hospital 19 June 1973.)

(Accepted 26 August 1988)
How common is death during sexual intercourse, and when this occurs what are the likely causes?

There are no statistics on death during sexual intercourse; obviously many are not reported as such. Any figures that might be available would be gross underreporting.

In medicolegal practice, however, especially in a coroner's necropsy service, it is a regular, though perhaps not frequent, experience to be given a history that a person died during sexual intercourse. For obvious reasons, mainly embarrassment, many cases are not reported. Of cases in which such a history is offered the deceased is almost always the man and the death is precipitated by exertion, often of an acute nature and perhaps in people who otherwise never engage in violent exercise.

The most common cause of death is ischaemic heart disease, usually coronary artery disease or possibly hypertensive heart disease. A bout of violent sudden exercise raises the blood pressure and releases catecholamine substances into the bloodstream. But the emotional and physical stimuli occasioned by sexual intercourse create sudden rapid demands for oxygen that may not be met by the coronary circulation in the heart muscle. When sudden death occurs this is usually due to ventricular fibrillation from chronic myocardial ischaemia rather than any acute myocardial infarction, though when an infarct is already present the violent exercise of intercourse may precipitate death.

The other cause of sudden unexpected death during intercourse is subarachnoid haemorrhage, usually from a ruptured berry aneurysm on one of the cerebral arteries at the base of the brain. This cause is well known to neurosurgeons and accident departments. The rapid rise in blood pressure caused by the acute exertion of intercourse may rupture this small blister, resulting in rapid if not instantaneous death.

Coronary artery disease is more common in men during the sexually active phase of life than it is in women, but both men and women have an approximately equal incidence of berry aneurysms. Exertion is, however, commoner in men so death is more likely in them.

There are many other causes of sudden death any of which could occur during sexual intercourse, again precipitated by exertion. I have never seen a death reported in a woman during intercourse, though there may be some. The possibility of death from "vagal inhibition"-that is, a purely nervous reaction due to heightened emotion, etc-is theoretically possible but highly unlikely. Unnatural events, such as pressure on the neck or even on the body causing breathing difficulties, are possible but rare causes of death.

BERNARD KNIGHT, forensic pathologist, Cardiff

A young woman with a husband of similar age has had her first baby and it has Down's syndrome. What are the risks of a similar outcome to her next pregnancy?

The first step is to establish the chromosome pattern of the baby with Down's syndrome. If the child has trisomy 21 , which is the karyotype found in over $95 \%$ of all children with Down's syndrome, the risk of a similar outcome in her next pregnancy is low. Two studies have shown a risk of the order of $1-2 \%$ of Down's syndrome occurring in subsequent children born to mothers who first bore a Down's syndrome baby when young. ${ }^{12}$ Above a maternal age of 40 the risk depends on the maternal age alone.

If the karyotype of the baby shows that it has translocation Down's syndrome-the additional chromosome 21 is attached to another chromosome - blood from both parents should be analysed to see if either is a translocation carrier. Rarely, a parent is found to have both number $21 \mathrm{~s}$ joined together, and in this unfortunate event all offspring will have Down's syndrome. If, however, one chromosome 21 is attached to another chromosome (commonly chromosome 14) the observed risk for a woman with this type of translocation having a chromosomally unbalanced offspring is $10-15 \%,{ }^{3}$ and for a man it is $2-3 \%$.

Parents of all children with Down's syndrome can benefit from genetic counselling, and this is strongly recommended when either parent is a translocation carrier. - DIAN DONNAI, clinical geneticist, Manchester

Richards BW. The recurrence of mongolism in sibships. $\mathcal{F}$ Ment Defic Res 1977;21:5-23. 2 Carter CO, Evans KA. Risks of parents who had one child with Down's syndrome having another child similarly affected. Lancet $1961 ;$ ii: $785-8$.

3 Boue A, Gallano PA. Collaborative study of the segregation of inherited chromosome structurat rearrangements in 1356 prenatal diagnoses. Prenat Diagn 1984:4:45-67.

4 Gorlin RJ. Classical chromosome disorders. In: Yunis JJ, ed. New chromosomal syndromes. London: Academic Press, 1977:59-117. 